\title{
National Ignition Facility Sub-System Design Requirements Supervisory Control Software SSDR 1.5.2
}

\author{
J. Woodruff \\ P. VanArsdall \\ E. Bliss
}

August 29, 1996

This is an informal report intended primarily for internal or limited external distribution. The opinions and conclusions stated are those of the author and may or may not be those of the Laboratory.

Work performed under the auopices of the U.S. Department of Energy by the Lawrence Livermore National Laboratory under Contract W-7405-Eng-48. 


\section{DISCLAIMER}

This document was prepared as an account of work sponsored by an agency of the United States Government. Neither the Urited States Government nor the University of California nor any of their employees, makes any warranty, express or implied, or assumes any legal liability or responsibility for the accuracy, completeness, or usefulness of any information, apparatus, product, or process disclosed, or represents that its use would not infringe privately owned rights. Reference herein to any specific commercial product, process, or service by trade name, trademark, manufacturer, or otherwise, does not necessarily constitute or imply its endorsement, recommendation, or favoring by the United States Government or the University of California. The views and opinions of authors expressed herein do not necessarily state or reflect those of the United States Government or the University of California, and shall not be used for advertising or product endorsement purposes.

This report has been reproduced directly from the best available copy.

Available to DOE and DOE contractors from the Office of Scientific and Technical Information

P.O. Box 62, Oak Ridge, TN 37831

Prices available from (615) 576-8401, FTS 626-8401

Available to the public from the

National Technical Information Service

U.S. Department of Commerce

5285 Port Royal Rd.,

Springfield, VA 22161 


\title{
National Ignition Facility
}

\section{Sub-System Design Requirements}

\author{
Supervisory Control Software \\ SSDR 1.5.2
}

Revision 2

29 August 96

Prepared by:

J. Woodruff, Supervisory Software Team Leader

Date

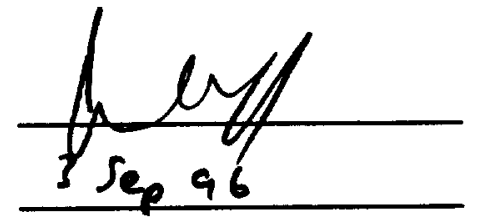

P. VanArsdall, Integrated Computer Controls

Lead Engineer

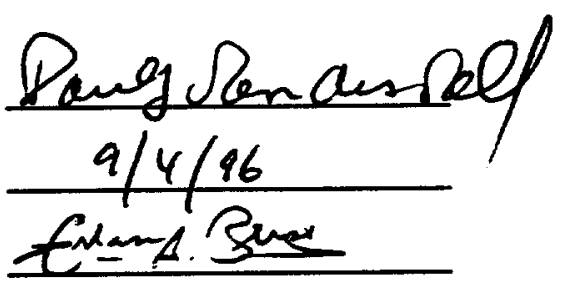

E. Bliss, System Controls System Engineer

Date

Date

$$
10 / 5 / 96
$$

Special Equipment Engineering Approval:

R. Sawicki, NIF Associate Project Engineer

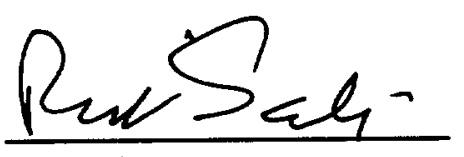

Date $10 / 21 / 96$

Engineering Review Board Approval:

s. Kumpan, NIF Project Engineer $\frac{\text { S.A. Kumpan }}{\text { Approval Date } 1 \cdot / 2 \cdot / 96}$ 


\section{Table of Contents}

\begin{tabular}{|c|c|}
\hline Paraqraph & Title \\
\hline 1.0 & Scope \\
\hline 2.0 & Applicable Documents \\
\hline 2.1 & Applicable NIF Project Documents \\
\hline 2.2 & Applicable US Government Orders and Standards \\
\hline 2.3 & Applicable National Consensus Codes and Standards \\
\hline 2.4 & Applicable LLNL Standards \\
\hline 2.5 & Supporting Documentation Standards \\
\hline 2.6 & References \\
\hline 3.0 & Requirements and Verification \\
\hline 3.1 & System Definition \\
\hline 3.1 .1 & System Description \\
\hline 3.1 .2 & System Functions \\
\hline 3.1 .3 & System Diagrams \\
\hline 3.1 .3 .1 & Supervisory Software Relationship to FEP Software \\
\hline 3.1 .3 .2 & Supervisory Control and FEP Software Hierarchy \\
\hline 3.1 .4 & System Interfaces \\
\hline 3.1 .5 & Major Subsystems, Supervisory Control Software- WBS 1.5.2 \\
\hline 3.2 .00 & Supervisory Control Software, Functional Requirements \\
\hline 3.2 .01 & Supervisory Control Software, Application Software \\
\hline 3.2 .02 & Supervisory Control Software, Look and Feel \\
\hline 3.2 .03 & Supervisory Control Software, GUI Application \\
\hline 3.2 .04 & Supervisory Control Software, Software Languages \\
\hline 3.2 .04 .1 & Supervisory Control Software, Standard Software Language, Ada \\
\hline 3.2 .04 .2 & Supervisory Control Software, Secondary Software Language, C/C++ \\
\hline 3.2 .04 .3 & Supervisory Control Software, QA Level Requirements \\
\hline 3.2 .05 & Supervisory Control Software, Machine Interlocks \\
\hline 3.2 .06 & Supervisory Control Software, Hardware Platform \\
\hline 3.2 .07 & Supervisory Control Software, On-line Configuration \\
\hline 3.2 .08 & Supervisory Control Software, Diagnostic Suite Definition \\
\hline 3.2 .09 & Supervisory Control Software, Pre-Shot Requirements \\
\hline 3.2 .10 & Supervisory Control Software, Shot Time Requirements \\
\hline 3.2 .11 & Software Requirements Specification (SRS) \\
\hline 3.2 .12 & Supervisory Control Software, Access to Distributed Control Points \\
\hline 3.2 .13 & Modes of Operation, Segmented and Concurrent Operation \\
\hline 3.2 .14 & Supervisory Control Software, Documentation and Manuals \\
\hline 3.2 .15 & Lifetime, Replaceablity, Reliability, Availability, Maintainability \\
\hline 3.2 .15 .1 & Lifetime \\
\hline 3.2 .15 .2 & Replaceablity \\
\hline 3.2 .15 .3 & Reliability \\
\hline 3.2 .15 .4 & Availability \\
\hline 3.2 .15 .5 & Maintainability \\
\hline 3.2 .16 & Recovery From Abnormal Event \\
\hline 3.2 .17 & Human Factors \\
\hline 3.4 & Logistics \\
\hline 3.4 .1 & Maintenance \\
\hline 6.0 & Revision Record \\
\hline
\end{tabular}




\subsection{Scope}

This System Design Requirement document establishes the performance, design, development, and test requirements for the Supervisory Control Software, WBS 1.5.2, which is part of the NIF Integrated Computer Control System (ICCS). This document responds directly to the requirements detailed in ICCS (WBS 1.5) which is the document directly above.

\subsection{Applicable Documents}

This section lists DOE orders, codes, and standards which are applicable to the NIF Integrated Computer Control System. The applicable portions of these documents apply. Applicable LLNL standards are being considered contingent upon the decision of final site selection.

\subsection{Applicable NIF Project Documents}

National Ignition Facility Functional Requirements and Primary Criteria, Revision 1.4, Mar 1996.

\subsection{Applicable US Government Orders and Standards}

US. Government DOE General Orders: (fd = flowdown from SDR004, nfd = no flowdown)

DOE 5700.6C-Quality Assurance (fd)

US. Government DOE Orders relating to Safeguards and Security:

None apply to this document.

\subsection{Applicable National Consensus Codes and Standards}

General Standards:

None apply to this document.

Safety Standards:

None apply to this document.

Software and Electronic Standards:

Ethernet IEEE-802.3 Local Area Network for Data Communications

FDDI

RS-232C

RS-485

IEEE-488

Fiber Distributed Data Interface, ANSI Standard X3.139-1987

EIA Serial interface standard

EIA Multi-drop serial interface standard

Standard Digital Interface for Programmable Instrumentation, ANSI/EEE Std 488.1-1987 and

ANSI/IEEE Std 488.2-1987

VMEbus

RS-170

IEEE-1014

Ada 83

Ada 95

EIA Video interface standard

$\mathrm{X} 11$

OSF/Motif

ANSI/MIL-STD-1815A-1983, programming language

International Standard ANSI/ISO/IEC-8652:1995, January 1995

Postscript

$\mathrm{X}$ Window System, Version 11, windows graphics standard, MIT X Consortium

POSIX

TCP/IP

Motif graphical user interface, Open Systems Foundation

Text and graphics printing language, Adobe Systems Inc.

IEEE-1003 portable application programming environment

Protocol stack for network communications

OSUISO

OSF/DCE

OSF/DME

Open Systems Interconnect protocol stack for network communications

Distributed Computing Environment, Open Systems Foundation

Distributed Management Environment, Open Systems Foundation

\subsection{Applicable LLNL Standards}

None apply to this document. 


\subsection{Supporting Documentation Standards}

Instrument Society of America, ISA-S5.1, Instrumentation Symbols and Identification

Instrument Society of America, ISA-S5.2, Binary Logic Diagrams for Process Operations

Instrument Society of America, ISA-S5.3, Graphics Symbols for Distributed Control/Shared Display

Instrumentation, Logic and Computer Systems

Instrument Society of America, ISA-S5.4, Instrument Loop Diagrams

Instrument Society of America, ISA-S5.5, Graphics Symbols for Process Displays

ANSI/IEEE Std 730.1-1989, IEEE Standard for Software Quality Assurance Plans

Software Guidelines Standards, Practices, and Conventions (Final DRAFT), Applications Development

Department, Lawrence Livermore National Laboratory, August 10, 1992

ANSI/IEEE Std 830-1984, IEEE Guide for Software Requirements Specification

ANSI/IEEE Std 1016-1987, IEEE Recommended Practice for Software Design Descriptions

ANSI/IEEE Std 828-1983, IEEE Standard for Software Configuration Management Plans

ANSI/IEEE Std 982.1-1988, IEEE Standard Dictionary for Measures to Produce Reliable Software

ANSI/IEEE Std 982.2-1988, IEEE Guide for the Use of IEEE Standard Dictionary of Measures to Produce

Reliable Software

The Software Productivity Consortium, Ada Quality and Style Guidelines for Professional Programmers

ANSI/IEEE Std 1063-1987, IEEE Standard for Software User Documentation

\subsection{References}

NIF-LLNL-95-044/L-15958-2, National Ignition Facility Quality Assurance Program Plan, September 1995

NIF-LLNL-94-017/L-15958-5, NIF Ancillary Software Quality Assurance Plan, January 12, 1994

NIF-LLNL-93058, National Ignition Facility Functional Requirements and Primary Criteria

\subsection{Requirements and Verification}

\subsection{System Definition}

\subsubsection{System Description}

This system provides supervisory software for integrated control of the distributed subsystems, manual operator controls, and displays and reports laser and target area shot data.

Application software is organized as subsystems. Alignment, laser diagnostics, power conditioning, optical pulse generation, and target diagnostics are each assigned a primary operator console in the control room. A sixth subsystem is devoted to experiment configuration and overall integration functions. All subsystem controls and status are provided with graphic user interfaces suitable to operator action.

\subsubsection{System Functions}




\subsubsection{System Diagrams}

\subsubsection{Supervisory Software Relationship to FEP Software}

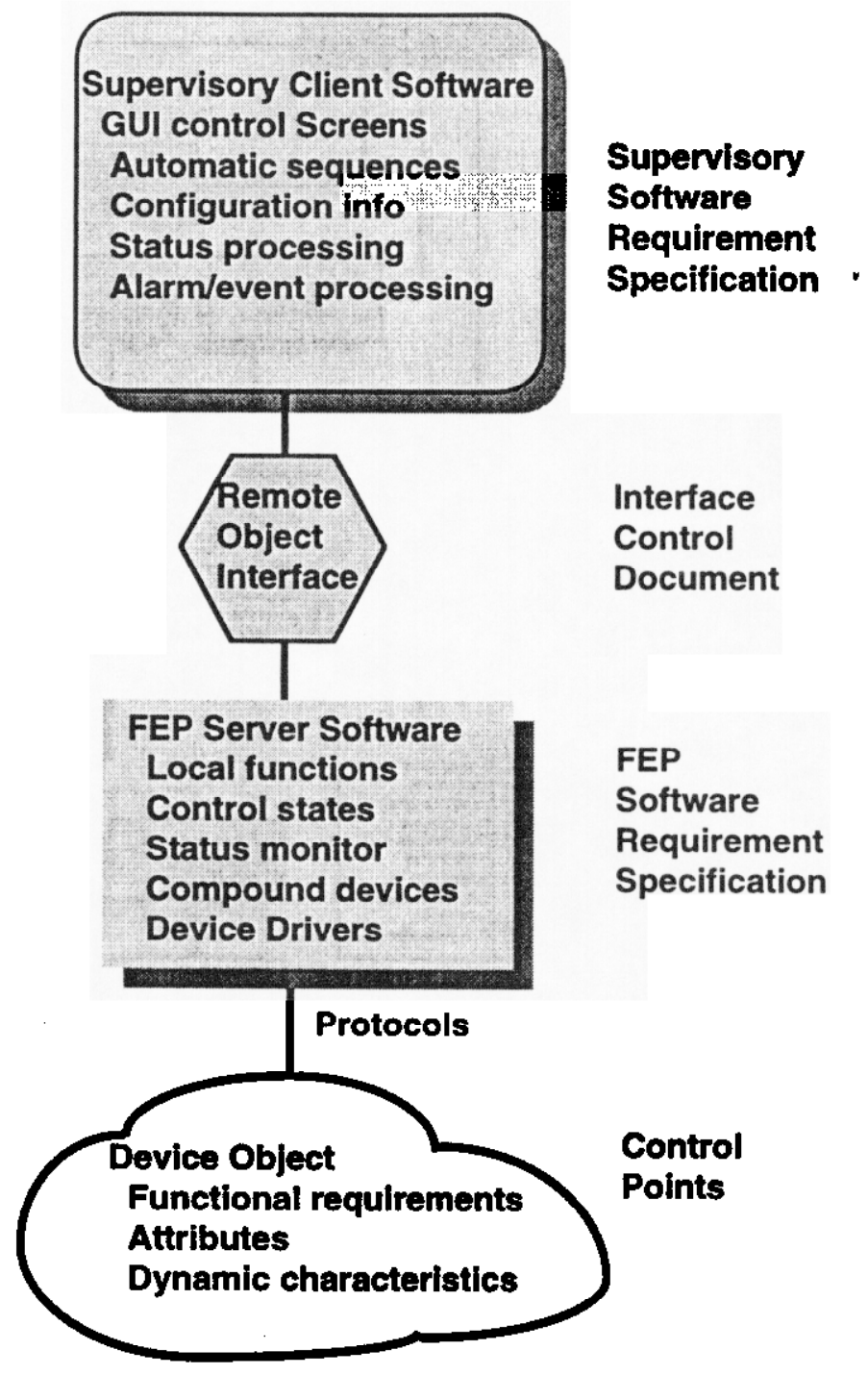




\subsubsection{Supervisory Control and FEP Software Hierarchy}

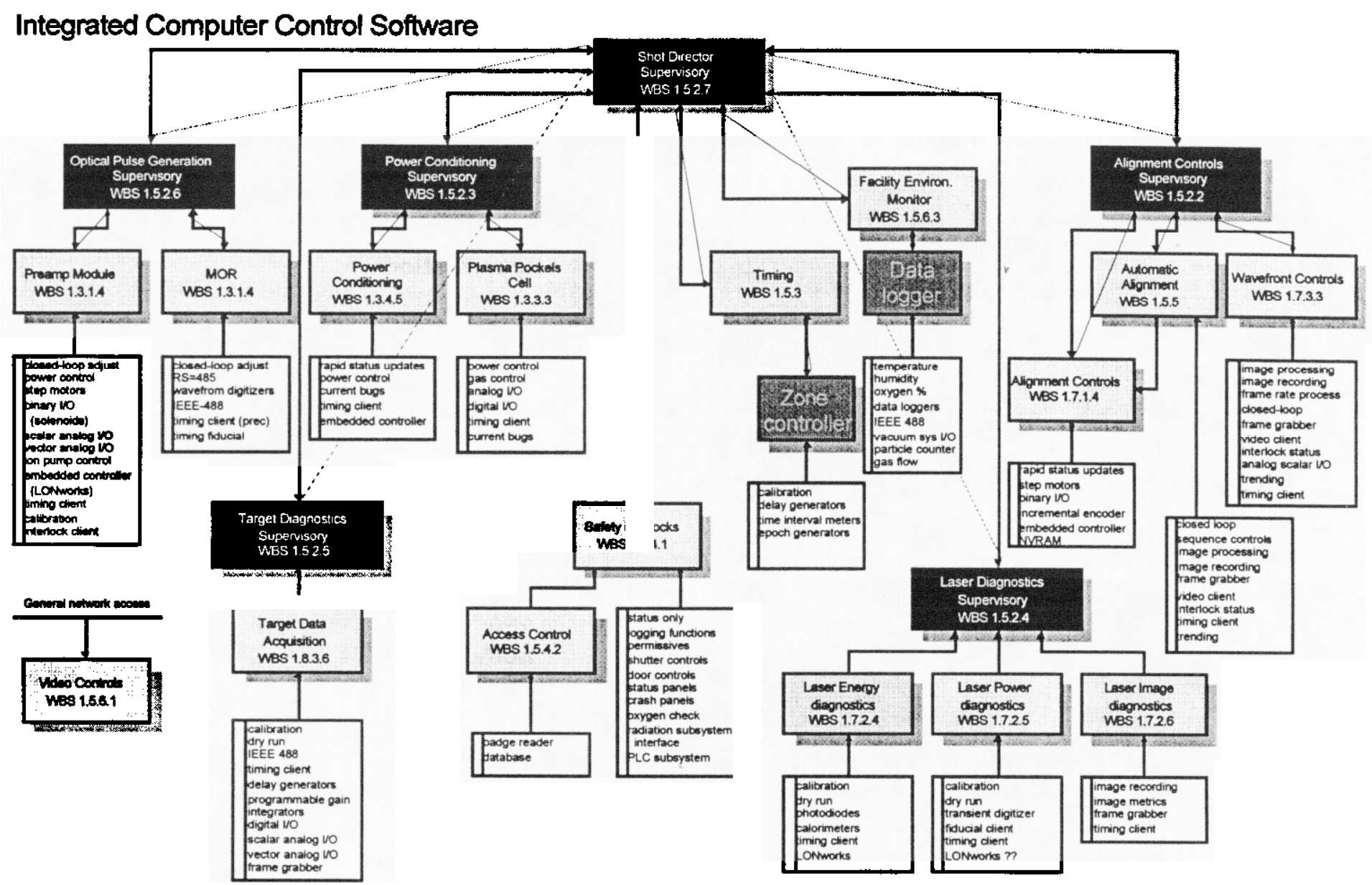




\subsubsection{System Interfaces}

The ICCS Supervisory Control Software has interfaces to the following WBS systems:

$\begin{array}{ll}\text { WBS } 1.5 .3 & \text { Integrated Timing System (FEP) } \\ \text { WBS } 1.5 .4 .1 & \text { Integrated Safety System (FEP) } \\ \text { WBS } 1.5 .4 .2 & \text { Integrated Safety System, Access Control (FEP) } \\ \text { WBS } 1.5 .5 & \text { Automatic Alignment (FEP) } \\ \text { WBS } 1.5 .6 .3 & \text { Facility Environmental Monitor } \\ \text { WBS } 1.5 .6 .1 & \text { Video Distribution (FEP) } \\ \text { WBS } 1.563 & \text { Environmental Monitor (FEP) } \\ \text { WBS } 1.8 .6 .3 & \text { Target Auxiliary Systems (FEP) } \\ \text { WBS } 1.8 .3 .11 & \text { Target Diagnostics Control Room (FEP) } \\ \text { WBS } 1.7 .3 & \text { Wavefront Control (FEP) } \\ \text { WBS } 1.7 .2 & \text { Beam Diagnostics (FEP) } \\ \text { WBS } 1.7 .1 & \text { Alignment Systems (FEP) } \\ \text { WBS } 1.3 .4 & \text { Power Conditioning (FEP) } \\ \text { WBS } 1.3 .3 & \text { Pockels Cell System (FEP) } \\ \text { WBS } 1.3 .1 & \text { OPG (FEP) } \\ \text { WBS } 1.3 .1 & \text { OPG Modulator (FEP) } \\ \text { WBS } 1.3 .1 .1 & \text { OPG/MOR (FEP) } \\ \text { WBS } 1.3 .1 .5 & \text { OPG/Preamp (FEP) }\end{array}$

3.1.5 Major Subsystems, Supervisory Control Software - WBS 1.5.2 Consists of WBSs:

1.5.2.1 System Integration Software

1.5.2.2 Alignment Controls Software

1.5.2.3 Power Conditioning Software

1.5.2.4 Laser Diagnostics Software

1.5.2.5 Target Diagnostics Software

1.5.2.6 Master Oscillator and Preamplifier Software

1.5.2.7 Shot Director Controls and Status Software 


\subsubsection{Supervisory Control Software, Functional Requirements}

The Supervisory Control Software

- provides supervisory software for integrated control of the distributed subsystems:

- power conditioning

- laser alignment and wave front controls

- laser beam diagnostics

- target diagnostics

- optical pulse generation

- provides manual operator controls for maintenance

- displays laser- and target-area configuration schematically

- displays and report laser- and target-area shot data

- provides special motor-slewing operator controls for alignment

- configures laser- and target-area sensors and instruments using FEP capabilities, store shot configuration as part of shot data

- coordinates FEP-level machine interlocks to protect against component damage caused by improper operation

- retrieves data from distributed FEPs

- provides reusable integration software for upper-level systems

- interprocess communication

- distributed shot number

- event logging

- alarm processing

- sequences slower control elements not connected to hardware timing system

- reduces and stores laser diagnostic data in on-line database

- analyzes laser performance and models power balance

- processes selected target diagnostics data for rapid assessment of experimental results

- coordinates automatic alignment system

\subsubsection{Supervisory Control Software, Application Software}

Detailed requirements for each major element of the supervisory software shall be documented in a separate Software Requirements Specification (SRS). The SRS shall specify requirements including performance, concurrency, persistence, and other dynamic specifications that may imply system partitioning or a particular method of implementation. Each SRS shall describe the functional requirements that the subsystem must provide, including:

- services that are required by the respective Front End Processors

- configuration data that characterize equipment being controlled

- user interfaces

- data processing and archival

- automatic sequencing

- status and alarm processing

- data logging and trending.

\subsubsection{Supervisory Control Software, Look and Feel}

All application GUIs shall provide a consistent look and feel across all subsystems to ameliorate the potential of operator errors. The look (presentation of information) and feel (way in which the operator interacts with the application) shall follow the similar conventions throughout the control system, including use of color, use of symbols, and style of operator input.

\subsubsection{Supervisory Control Software, GUI Application}

The applications GUI shall allow the operator to control the layout of the workstation, including number, sizing and placement of windows. 
As a goal, all GUI applications should attempt to allow recovery of an operator defined screen layout configuration, on a per-operator basis. That is, an individual operator should be able to define a screen "window" configuration, and retrieve the layout, to effectively customize the screen, and arrive at a familiar operating presentation at runtime.

\subsubsection{Supervisory Control Software, Software Languages}

\subsubsection{Supervisory Control Software, Standard Software Language, Ada}

The standard software language shall be Ada. Exceptions shall be by design review.

\subsubsection{Supervisory Control Software, Secondary Software Language, C/C++}

The secondary software language shall be $\mathrm{C} / \mathrm{C}++$. Exceptions shall be by design roview.

\subsubsection{Supervisory Control Software, QA Level Requirements}

The Supervisory Control Software shall adhere to the following Quality Level specifications. Reference for QA Level is the NIF QA Plan as stated in paragraph 2.6 of this document.
WBS 1.5.2.1 System Integration Software
WBS 1.5.2.2 Alignment Controls Software
WBS 1.5.2.3 Power Conditioning Software
WBS 1.5.2.4 Laser Diagnostics Software
WBS 1.5.2.5 Target Diagnostics Software
WBS 1.5.2.6 Master Oscillator and Preamplifier Software
WBS 1.5.2.7 Shot Director Controls and Status Software
Q-Level 2
Q-Level 3
Q-Level 3
Q-Level 2
Q-Level 3
Q-Level 3
Q-Level 3

\subsubsection{Supervisory Control Software, Machine Interlocks}

Machine interlocks, via a configuration database, shall be used to keep the beam path clear, and assure that attenuators or gain settings are established before a shot so that components cannot be damaged. Other machine interlock functions shall be implemented as needed.

\subsubsection{Supervisory Control Software, Hardware Platform}

The Supervisory Software shall operate in the hardware environment specified in ICCS, Computer Systems SSDR

\subsubsection{Supervisory Control Software, On-line Configuration}

Supervisory Control Software shall utilize a configuration database to configure all dynamic control point operating parameters (such as calibrations, I/O channels, etc.).

\subsubsection{Supervisory Control Software, Diagnostic Suite Definition}

The Target Diagnostic Instruments Suite and setup for each instrument shall be defined via a database configuration file.

\subsubsection{Supervisory Control Software, Pre-Shot Requirements}

- ICCS shall provide supervisory software for integrated control of five distributed subsystems:

- power conditioning

- optical pulse generation

- laser beam control, including alignment and wave front controls

- laser beam diagnostics

- target diagnostics 
- For each subsystem, controls shall be provided to the operator that enable the following functions:

- provide manual operator controls for installation, maintenance and problem diagnosis

- examine the status of each controlled device

- coordinate FEP-level machine interlocks to protect against component damage caused by improper operation

- provide display of status data from auxiliary systems (gas pressures, coolant fluid flow, vacuum system, radiation safety monitors)

- report events to the operator

- display laser- and target-area equipment configuration schematically

- report and archive equipment- and safety-interlock status

- maintain an audit trail of operator actions and equipment responses

- assure the orderly coordination of activities performed by different operators

- archive beam diagnostic images as required to support damage inspection

- support the diagnosis of failures in the software, computer systems, stored data, and network

- archive laser performance data to facilitate performance tuning on later shots

\subsubsection{Supervisory Control Software, Shot Time Requirements}

- ICCS shall coordinate all subsystem activities to execute a shot under the direction of the Shot Director:

- prepare the laser to execute a shot

- sequence such slower control elements as are not connected to the hardware timing system

- reduce and store laser diagnostic data in on-line database

- collect, display, and archive data generated in a shot

- store shot configuration as part of shot data

- analyze laser performance and model and provide power balance feedback to the OPG

- process selected target diagnostics data for rapid assessment of experimental results

- analyze wavefront data

- analyze Laser Diagnostic data

\subsubsection{Software Requirements Specification (SRS)}

Detailed requirements for each major element of the supervisory software shall be documented in a separate Software Requirements Specification. The SRS shall include functional requirements for user interfaces, data processing and archival, automatic sequencing, control system configuration, status processing, alarm processing, and data logging and trending.

The SRS shall also include performance, persistence, concurrency, or other dynamic requirements as well as other architectural requirements that may imply system partitioning or a particular method of implementation.

\subsubsection{Supervisory Control Software, Access to Distributed Control Points}

Access to all distributed control points that are integrated into the control system shall be made by Front End Processors that implement the hardware-level interface to the control points. The FEP software shall implement those functional requirements that are determined by requirements analysis to be allocated to the FEP layer in the controls architecture. The requirements analysis shall be guided by the physical properties and performance constraints of the control hardware, and by those operational scenarios requiring operation independent of the supervisory software or local control.

A separate Software Requirements Specification (SRS) shall be provided for each FEP. These SRS documents shall be used to further define the requirements of the supervisory software. 


\subsubsection{Modes of Operation, Segmented and Concurrent Operation}

The Supervisory Control Software shall support several modes of operation including: Configuration Setup

Preshot-alignment

Shot Countdown

Post-shot data collection and archival

Post-shot data reduction and presentation

Maintenance

Partial laser system operation

The Supervisory Control Software shall be capable of operating the NIF in a segmented mode with the segments functioning concurrently in different configurations. As an example, a portion of the laser may be under maintenance or construction and the rest of the laser operational. The Supervisory Control Software shall support the area under construction with appropriate test sequences, diagnostics and construction debugging tools, while simultaneously supporting shot sequences on the operational segment of the laser.

\subsubsection{Supervisory Control Software, Documentation and Manuals}

Documentation and manuals shall be provided to:

- Train and serve as a reference for Operations Staff

- Serve as a reference for future software development staff to facilitate modifications and additions that will be required over the life of the project.

The Supervisory Control Software System shall provide sufficient documentation to comply with the NIF Quality Assurance Plan, and DOE Order 5700.6C, Quality Assurance, Criterion-4 Documents and Records, which states: "Documents shall be prepared, reviewed, approved, issued, used and revised to prescribe processes, specify requirements or establish design. Records shall be specified, prepared, reviewed approved and maintained."

Examples of documents that should be controlled include drawings, data files, calculations, specifications, computer codes, purchase orders, vendor supplied documents, procedures, work records and data sheets and test records. Revisions should be reviewed by the organizations that originally prepared and approved the documents. Controlled documents should be distributed to those doing the work.

\subsubsection{Lifetime, Replaceablity, Reliability, Availability, Maintainability}

\subsubsection{Lifetime}

Lifetime: The Supervisory Control Software shall operate for 30 years.

\subsubsection{Replaceablity}

Replaceability: Any portion of the Supervisory Control Software which cannot reasonably be designed for 30 year lifetime shall be designed to be replaced or repaired at reasonable cost in a timely manner consistent with the overall availability of the System.

\subsubsection{Reliability}

Reliability: The Supervisory Control Software shall have an overall reliability of $99.70 \%$. Reliability is defined as the probability of meeting the minimum requirements of the experiment per no-yield shot.

\subsubsection{Availability}

Availability: The Supervisory Control Software shall have a shot availability of at least $97.22 \%$. The Supervisory Control Software is unavailable when it is undergoing unplanned maintenance. Unplanned maintenance includes failure detection and active repair as well as logistic and administrative downtimes. 


\subsubsection{Maintainability}

Maintainability: The Supervisory Control Software shall have a scheduled maintenance plan that fits within an overall annual plant goal of 69 days. The unplanned maintenance goal is 7.5 days per year. Opportunistic maintenance activities are performed between shots and during other system downtimes.

\subsubsection{Recovery From Abnormal Event}

The time required for the Supervisory Control Software to recover from any abnormal event shall be less than the maximum times cited below, as a function of the expected yearly frequency of occurrence of the event.

\begin{tabular}{cc} 
Expected Frequency of Occurrence Per Year. $F$ & Maximum Recovery Time \\
\hline $\mathrm{F} \geq 1$ & 24 hours \\
$1>\mathrm{F}>1 \mathrm{e}-2$ & 1 week \\
$1 \mathrm{e}-2>\mathrm{F} \geq 5 \mathrm{e}-4$ & 3 months
\end{tabular}

Probabilities listed in DOE-STD-1020-94 shall be used for natural phenomena.

For frequent events, the maximum allowed recovery time may be restricted by availability requirements to be less than that shown in the table above.

To meet the above Maximum Recovery Time requirements, Supervisory Controls shall maintain an off-site (other than the NIF facility) backup storage facility.

\subsubsection{Human Factors}

The Supervisory Control Software shall be designed in an ergonometric fashion to ensure that reliability during operation and maintenance is sustained at a level consistent with meeting overall availability and reliability objectives. Consistency in displays, warnings, and human interfaces should be maintained throughout the Supervisory Control Software and, if possible, throughout the NIF facility (i.e., GUI displays, access ports, tooling).

\subsection{Logistics}

\subsubsection{Maintenance}

As a part of the design/construction project, the Supervisory Control Software shall provide all equipment required to inspect, service, and maintain all subsystems within the Supervisory Control Software to meet the maintainability and availability requirements. Maintenance equipment shall include software maintenance tools, software backup tools, etc., and other special tools not otherwise available within the NIF, that are necessary to perform any planned (scheduled or unscheduled) maintenance activity.

\subsection{Revision Record}

\section{Rev Date Change by Description}

\section{letter}

$\begin{array}{lll}\text { A } & \text { 12Mar96 } & \text { Severyn } \\ \text { A } & \text { 30May96 } & \text { Severyn } \\ 2 & \text { 06Aug96 } & \text { Severyn } \\ 2 & \text { 20Aug96 } & \text { Severyn } \\ & & \\ 2 & \text { 28Aug96 } & \text { Clasen } \\ 2 & \text { 29Aug96 } & \text { Severyn }\end{array}$

Convert to FileMaker, update

Post Mid Title-1 update

para 2.6, update QA Plan ref

para 3.2.04.3, update $Q A$ levels

para 2.2, was empty, added ref to QA DOE Order.

para 2.2, 2.3,2.4, stated that some sections of these paragraphs do not have standards that apply to this document.

Convert to Word

Call rev B= rev 2 to match Sherpa.

Deleted "Supervisory Control Software" from many para. titles. 


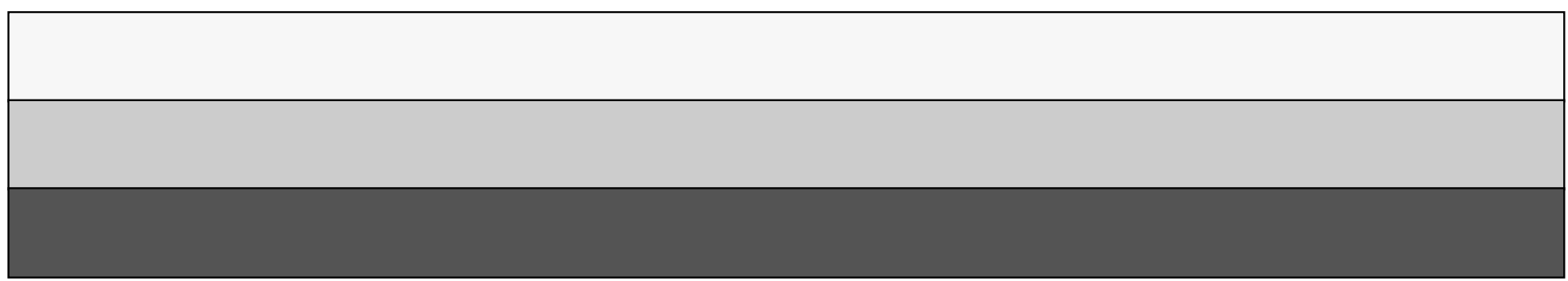

